DOI: $10.19195 / 0137-1150.169 .9$

Data przesłania artykułu: 22.01 .2018

Data akceptacji artykułu: 15.04.2018

\title{
MICHAIL CHMELEVSKIJ
}

Petersburski Uniwersytet Państwowy, Rosja

\section{Роль процесса актуализации ориентализмов в формировании современного сараевского городского койне}

Сараево - один из крупнейших политических, экономических и культурных центров Балканского полуострова, столица современной Боснии и Герцеговины. Его история уходит в глубь столетий - уже с XIII века этот город становится средоточием различных геополитических, культурных и религиозных влияний, что в результате придало неповторимый колорит и своеобразие не только самому городу, но и - шире - всему центрально-балканскому региону Боснии и Герцеговины. Благодаря такому соединению в одном месте восточной — мусульманской, западной — католической, византийской — православной и иудейской культур Сараево получил у балканских народов второе метафорическое название Evropski Jeruzalem.

В результате распространения ислама среди славянского населения Боснийского вилайета наряду с миром Slavia Orthodoxa и Slavia Latina на Балканском полуострове (вместе с помаками в Болгарии) формируется еще один - славяно-мусульманский мир, который в настоящее время насчитывает около 1,8 млн человек. Данный исторический факт ярко иллюстрирует современный фразеологизм pade Bosna ko dozrelo jabuko u sultanovo krilo - „пала Босния, как созревшее яблоко, в объятия султана”, который в современном языке употребляется в значении 'свершилось что-либо неминуемое и заранее предрешенное, чему невозможно было противостоять'. О том, как мусульманская религия особым образом приживалась в Боснии

* Работа выполнена при финансовой поддержке Российского фонда фундаментальных исследований. Проект № 18-012-00754; шифр ИАС 31.15.69.2018. 
и подстраивалась под нравы, устои и традиции местного славянского населения, образно свидетельствует и поговорка: Bosna je potekla šerbetom, ali i muselezom — „И потекли по Боснии не только шербет, но и вино” (где турцизмы šerbet - 'вода, подслащенная медом' и muselez - 'слабое вино из недозрелого винограда'). Пословица хранит в себе образ пришедшего вместе с исламом запрета на употребление алкогольных напитков, которые „помутняют дух и разум”, но, с другой стороны, подмечает стремление боснийцев сохранить привычный уклад жизни и традиции виноделия, т. е. принимая новое, не утратить при этом и старое, что подтверждает еще одна ироничная пословица: religije se mijenjaju, pivo i vino ostaje — ,религии меняются, а пиво и вино остаются".

На религиозном принципе, который в данном регионе всегда имел основополагающее значение в процессе формирования отдельных народов Южной Славии, в XV веке здесь зарождается еще одна нация славян-мусульман, боснийских мусульман, босняков (или бошняков), в прошлом именовавших себя также турками, а во второй половине XX века возникает официальный термин для наименования данного южнославянского народа — мусульмане (Muslimani).

С лингвистической точки зрения, результатом исламизации славянских народов Балкан стало проникновение значительного числа ориентализмов (помимо самих турцизмов, в основном через турецкий или напрямую, проникают также заимствования из арабского и персидского языков). Отметим, что, находясь под властью Османской империи, все южные славяне, в том числе и православные, и католики, в той или иной степени заимствуют турцизмы на всех уровнях языка, их распространенность можно проследить на всей территории Южной Славии. Многие из них уже давно перестали восприниматься как заимствования и нередко выступают в качестве маркеров специфичных славянских национальных культур (ćevapi, čorba, pare, džezva, budala, baksus, merak, inat, междометие bre и т. п.). Однако именно в языке боснийских мусульман ориентализмы отличаются наибольшей частотностью употребления по сравнению с остальным южнославянским языковым ареалом (нередко при наличии славянского эквивалента предпочтение отдается турцизму: ulica — sokak, prijatelj — jaran, tuga - sevdah, čaša - fildžan, voljeni - dilber, zadovoljstvo - ćejf и т. п.). При этом следует подчеркнуть, что процесс актуализации употребления турцизмов у боснийских мусульман начинается с 90-ых годов XX в. после распада Югославии и обретения Боснией и Герцеговиной государственной независимости, когда особо остро встали вопросы этнической самоидентификации, конфессиональной принадлежности и — как следствие - национального языка. Все это послужило современным политикам, деятелям культуры и лингвистам основанием для кодификации тнз. боснийского языка. Некогда бывшие регионализмами и архаизмами или относившиеся исключительно к узкой сфере религии или 
фольклора ориентализмы получили статус нормы и стали переходить в пласт разговорного языка или жаргонного употребления.

В настоящей статье мы не затрагиваем экстралингвистический вопрос боснийского языка, нас будут интересовать исключительно языковой материал и лингвистические факты, в частности роль ориентализмов и процесса их актуализации в становлении современного сараевского городского койне (который, как в разговорной речи, так и в лингвистической литературе также именуется sarajevski žargon, sarajevski sleng, čaršijski žargon - букв. 'уличный' от турецкого слова čaršija - 'центральная улица, торгово-ремесленный центр города', которое в свою очередь заимствовано из персидского čar-su — 'четыре стороны', т. е. место, где встречаются люди со всех сторон света. Упомянем здесь же, что центральная улица Сараева носит ставшее уже нарицательным название Baščaršija от турецкого $b a s ̌$ — 'главный, большой').

Как и любой крупный столичный город на Балканах, Сараево имеет свой узнаваемый и маркированный языковой код, характеризующийся особым статусом интердиалектного образования (в этом смысле сравним социально-языковые статусы загребского койне в Хорватии, белградского жаргона в Сербии или подгорицкого диалекта в Черногории). Специфику сараевского койне составляет совокупность характерных языковых черт, а именно: диалектологические особенности Сараевского кантона, региональное семантическое переосмысление отдельных лексических единиц, заимствования из немецкого языка и особо маркированный статус турцизмов и - шире - ориентализмов в повседневной речи жителей Сараево. В этом смысле следует отметить также актуальную тенденцию к расширению сферы употребления „сараевского языка”, который постепенно выходит за рамки разговорного общения и границы одного города и все чаще проникает в устный и письменный язык общегосударственных СМИ, политики, официально-делового общения, а также - посредством массовой культуры - отдельные характерные лексемы и выражения выходят за пределы Боснии и Герцеговины, сохраняя при этом в сознании реципиентов ассоциативную связь с местом своего происхождения. Так, характеризуя то или иное значение отдельных специфически боснийских языковых форм наши информанты из Сербии, Черногории и Хорватии сопровождали свои толкования такими уточнениями, как: Razumem, ali kod nas se tako ne kaže, to ćeš čuti samo и Bosni - „Я понимаю, но у нас так не говорят, это ты услышишь только в Боснии”, tako se kaže u Bosni — „так говорят в Боснии”, kako se kaže u Sarajevu... — „как говорят в Сараево...”, to је muslimanski izraz za... — „это мусульманское (т. е. боснийско-мусульманское) выражение для...” и т. п. ${ }^{1}$

1 Здесь и далее приводятся примеры, собранные и записанные нами у информантов в ходе полевых исследований в Боснии и Герцеговине с 2009 по 2018 гг., а также взятые из современных словарей, вышедших в последнее десятилетие (см. библиографию). 
В ходе проведенных нами полевых исследований разговорной речи боснийских мусульман нас интересовало живое (а не словарное) употребление именно тех ориентализмов, которые претерпели процесс семантического переосмысления внутри современного сараевского койне, что сформировало его специфику и колорит. Показательным примером вышесказанному является их живое употребление во фразеологизированных устойчивых сочетаниях, одним из компонентов которых выступает семантически переосмысленная турецкая, арабская или персидская по своему происхождению лексема. Так, турцизм džamija - 'мечеть' является общим для всего южнославянского языкового пространства, однако только в речи славянских мусульман, у которых данное понятие не является признаком чужеродной культуры, а наоборот, относится к повседневной жизни, мы встречаем такие устойчивые сочетания, как čisto kao u džamiji — „очень чисто”, или čuvati kao džamiju „очень беречь, хранить”, iz džamije bi ukrao - букв. 'он бы из мечети украл' - об искусном воре, для которого нет ничего святого. Аналогичный пример находим и с выражением ramazanski post, понятным носителям и других культур, но только в языке тех, для кого оно является обозначением культурологически ограниченной реалии, т. е. для славянских мусульман, мы обнаруживаем устойчивое сравнение trajati kao ramazanski post — „очень долго”. В связи с этим приведем еще один фразеологизм vikati sa munare - букв. 'кричать с минарета' в значении 'распространять какую-либо новость, весть, информацию как можно шире'. Нередко мы наблюдаем и явление лексического переосмысления ориентализмов, обозначающих религиозные понятия в исламе, которые в своем новом семантическом качестве и с приобретенным экспрессивным оттенком попадают в сферу жаргонного употребления. Так, к примеру, лексему $d z ̌ e n a z a-$ 'намаз, совершаемый в мечети по умершему' с переосмысленной семантикой можно встретить и в жаргоне спортивных болельщиков в значении 'поражение с большим результатом' или с иронично-экспрессивной окраской — в устойчивом сравнении veselo kao na dženazi в значении 'очень грустно, тихо'.

Остановимся подробнее на описании наиболее иллюстративных примеров функционирования переосмысленных и актуализированных ориентализмов в живой речи носителей современного сараевского койне.

Наряду с интернациональными фразеологическими моделями (встречающимися в большинстве европейских языков) - caru carevo, kralju kraljevo, bogu božje (ср. русск. Кесарю Кесарево, польск. Сеsarzowi, со cesarskie, a Bogu, co boskie) в языке боснийских мусульман мы находим варианты данной конструкции со специфичными для рассматриваемого региона компонентами-ориентализмами: agi agino (aga - 'вождь, правитель'), begu begovo (beg - „старший, главный правитель”) или, например, вариант с расширением — hadžiji hadžijino... a meni moje (hadžija — „хаджи”: 1. 'почетный титул мусульманина, совершившего паломничество в Мекку и Медину', 2. 'праведный человек', а в жаргоне - 3. 'богатый, знатный, 
авторитетный, выделяющийся каким-либо качеством человек'). Данный компонент в последнем значении употребляется в устойчивом сочетании Ili si bos, ili si hadžija — „Или ты бос, или хаджи” (ср. русск., например, Или пан, или пропал). Ироничность данному фразеологическому сочетанию в современном молодежном жаргоне дополнительно придает возможность его обыгрывания благодаря омонимии прилагательного bos — 'босой'и английского заимствования $b o s$ — ,босc”. В продолжение темы языковой игры внутри данного фразеологического сочетания приведем вариант жаргонного употребления с пейоративным компонентом: jebe se tebi što je hadžija bos - „тебе плевать, что хаджи босой”. Выражение используется в ситуации, когда говорящий потерял все, что имел, оказался в затруднительном положении, но он не находит сочувствия по этому поводу у своего собеседника.

Вышеприведенные примеры иллюстрируют процесс актуализации ориентализмов в силу экстралингвистических причин путем попадания в интернациональную фразеологическую модель, которые начинают жить в принимающем языке „своей жизнью”, порождая все новые значения и семантические вариации, вплоть до переносных и жаргонных. В связи с этим приведем такое устойчивое сравнение, как oči kao fildžani — о больших (от удивления или страха) глазах. Здесь fildžan (ср. славянские аналоги - čaša, šolja) - заимствование из турецкого языка в значении 'стакан, чашка, кружка, чаша' с тем отличием, что fildžan - традиционная кофейная чашка без ручки, подается на медном подносе вместе с туркой и является неотъемлемым и широко распространенным атрибутом традиции пития кофе, сопровождаемой многочисленными ритуалами, в том числе, и гаданием. Отметим, что данная лексема знакома и сербам, и хорватам, она включается в академические словари, правда, с пометой ,региональное, ориентальное”, тогда как для боснийских мусульман она является общеупотребительной и обозначает предмет повседневного быта. С тем же компонентом зафиксирован еще один фразеологизм - gledati u fildžan - букв. „смотреть в кофейную чашку” в значении 'гадать' (ср. gledati u šolju). Следует также отметить, что fildžan в сараевском жаргоне может семантически переосмысляться и в спортивном жаргоне обозначать кубок'. В данном значении слово довольно широко употребимо в ироническом фразеологизированном сочетании для наименования „дворового футбольного соревнования” — Fildžan liga (cp. русск. кубок лиги, польск. puchar ligi), при этом, оно также фиксируется и в сфере профессионального футбола — Fildžan liga UEFA, Bundes fildžan liga и т. п.

Как видно из примеров, ориентализмы выступают в переосмысленном значении как довольно частый компонент в устойчивых сочетаниях, в особенности с экспрессивным оттенком. Рассмотрим пример употребления ориентализма megdan (вариант mejdan). Данное заимствование проникло в язык многих славян посредством турецкого языка из арабского, в котором оно означает 'площадь, открытая равнинная местность', а также 'поле/арена боя, место для представлений’ (ср. название парка у центральной крепости 
в Белграде, а часто и самой крепости) - Kalemegdan, где тур. kale - 'крепость', т. е. букв. 'Замковая площадь'). Во времена Османской империи данная лексема употреблялась в Боснии также для обозначения спортивных соревнований (метание копья, камня, прыжки, забеги и т. п.) или зрелищных мероприятий, проводимых на главной площади города или на любой открытой местности по случаю больших праздников. Данный историзм закрепился в таких фразеологических единицах, как dobiti mejdan/dobiti na mejdanu - „выиграть соревнование/победить в поединке”, (po)dijeliti megdan s kim - „бороться (с кем-л.), соревноваться”, а также ostati na megdanu — „победить, стать победителем”.

В продолжение затронутой темы стоит также проанализировать и такие фразеологические сочетания, в которых одним из компонентов выступают ориентализмы, употребляемые исключительно в среде боснийских мусульман и отражающие особенности их менталитета, уклада жизни и конфессиональной принадлежности. Так, с принятием ислама в язык боснийских мусульман через турецкий попадает заимствование из персидского языка bajram — „мусульманский религиозный праздник”, которое, актуализировавшись в последние десятилетия, в разговорной речи употребляется для обозначения любого праздника вообще. Причем, данный компонент легко укладывается в интернациональные фразеологические модели: budali je svaki dan bajram — ,дураку каждый день праздник” (ср. русск. дураку каждый день праздник, польск. dla głupiego każdy dzień święto), ni bajrami nisu što su bili - „даже святые праздники уже не те, что были раньше” (говорится о ностальгии по старым временам), od bajrama do bajrama — „очень редко”.

Местный колорит отражает и фразеологизм с компонентом šenluk (тур. 'бал, веселье'): kad je šenluk, nek je šenluk! (по общей модели kad je bal nek je bal) с вариантами второй части: kad je šenluk, nek $i$ hala gori - „когда праздник — пусть хоть и зал горит” или kad je šenluk nek izgori i džamija — „когда праздник - пусть и мечеть сгорит”. Ареал употребления лексемы šenluk выходит за пределы сараевского жаргона, но именно в нем она получает дополнительное семантическое расширение - 'веселье, тусовка, пьянка'.

Особое значение в сараевском койне по частотности своего употребления получило и такое турецкое заимствование, как dernek, известное другим южным славянам, как: 1. 'собрание людей, сборище', 2. 'ярмарка'. В турецком данное слово имеет также значение 'общество, содружество, партнерство', которое употребляется и в переносном смысле 'большой праздник, веселье'. В современном сараевском жаргоне оно часто фиксируется в последнем метафорическом значении, синонимичном славянским zabava, žurka и ориентализму tulum (в жаргоне сараевской молодежи - 'вечеринка, тусовка, пьянка'), с тем отличием, что в семантике слова dernek заложена сема большого праздника, масштабной вечеринки с обязательным присутствием алкогольных напитков, устраиваемой с особым размахом 
и по особым случаям, как, например, юбилей, свадьба, окончание школы, рождение ребенка и т. п.

Для турцизма rahatluk трудно подобрать славянский эквивалент, он служит для обозначения концептуального для боснийского (и шире - южнославянского) менталитета понятия, объединяющего в себе состояние удовлетворения, полной расслабленности, удовольствия, беззаботности и умиротворения (ср. общеюжнославянский турцизм в схожем значении merak). Наши информанты характеризовали его так: „nepopisivi osjećaj opuštenosti, pokoja, bezbrižnosti, odnosno nirvana” — „неописуемое ощущение расслабленности, беззаботности или нирвана”. Данный компонент встречается в таких устойчивых сочетаниях, как: Bez zdravlja nema rahatluka — „Без здоровья нет удовольствия/расслабления/беззаботного времяпрепровождения” или: Bosanac nađe rahatluk $i$ na kraju svijeta — „босниец найдет «рахатлук» и на краю света". В Боснии также довольно частотным является употребление однокоренного прилагательного rahat, rahatni - 'спокойный, уютный' (в турецком языке - 'удобный, уютный, прелестный') и производного наречия: osjećao sam se kao golub, znači rahatno i lagahno - „я чувствовал себя, как голубь, то есть приятно, вольготно и легко”, rahatno pričati - „говорить сладкие речи”, Sarajevo je mirno i turist može rahatno hodati gradom - „Сараево - спокойное место, и турист может беззаботно/получая наслаждение, гулять по городу”, rahatno dijete - „хорошенький, милый ребенок” (ср. эквивалент: slatko dijete). Данное значение порождает переносное употребление лексемы rahatni - 'избалованный, неуравновешенный', что проявляется и во фразеологизме rahat od pameti, который употребляется для характеристики человека неустойчивого, неуравновешенного поведения, а также в значении 'безумный, сумасшедший' или 'флегматичный, безэмоциональный' Тот же корень мы находим в лексеме, обозначающей восточные сладости - rahatlokum (тур. букв. 'прелестный, лакомый кусочек'), который встречается во фразеологизме, возникшем в результате языковой игры: ni lokum više nije rahat о ностальгии по былым временам. Здесь же приведем и такие фразеологизмы, которые ярко иллюстрируют местный колорит: mrzeti kao hodža rahat-lokum — „очень любить” (букв. “ненавидеть, как ходжи рахат-лукум').

Еще один турцизм — deredža в значении 'религиозный статус, положение' иллюстрирует процесс выхода лексемы за рамки сугубо религиозной сферы и расширения сферы ее использования в живой речи, например, в качестве компонента во фразеологизме dobar (pošten/pametan) $i$ budala (glup) su na istoj deredži — „добрый (честный/умный) и дурак (глупый) все в одном положении" - говорится об уравнивании в правах разных по своим способностям и характеристикам людей; pasti na jednu deredžu „Уподобиться” (обычно с негативным значением). Данный фразеологизм в современном языке обрастает многочисленными вариантами, типа: Pariz i Sarajevo su na istoj deredži — „Париж и Сараево — на равных правах”, причем первая часть может свободно варьироваться: lud i hrabar — „сумасшед- 
ший и смелый”, dobar i jeban - здесь „хороший и придурковатый”, zdravi hodža $i$ zdravi hamal — „здоровый ходжа и здоровый носильщик/чернорабочий”), sva božija stvorenja kod Allaha — „все божии создания у Аллаха” - su na istoj deredži. Фразеологизм с компонентом-турцизмом создан по устойчивой модели na istoj su liniji/na istoj su razini — „на одном уровне”, na istoj su stazi — „на одной тропе” и т. п.

Иллюстративным примером выхода ориентализма за пределы сферы религии и расширения своего значения в разговорном языке может послу-

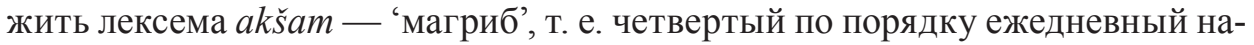
маз (молитва), совершаемый сразу после захода солнца. Время совершения этого намаза явилось определяющим при метафоризации значения данной лексемы в разговорном языке, напр., в таких устойчивых выражениях, как od sabaha do akšama — „от заката до рассвета” (где sabah - ‘фаджр', т. е. первый по порядку ежедневный намаз, совершаемый после восхода солнца). Здесь любопытно проследить процесс расширения жаргонного значе-

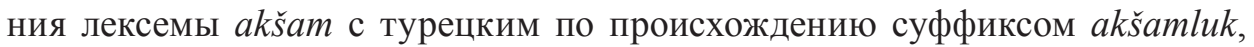
которая отражает местный колорит мусульманских славян и специфику укоренения ислама на славянской почве, — „вид отдыха — легкое времяпрепровождение в кругу друзей и близких, ведущих непринужденные беседы, обычно за едой и ракией, причем всегда в вечернее время суток". Отсюда возникают такие фразеологические сочетания, как akšamluk pijuckati — „попивать ракию в кругу друзей в вечернее время” или od akšamluka do $a k s ̌ a m l u k a$ — „наслаждаться жизнью”. В качестве иллюстрации приведем выдержку из эссе Боснийские хорваты писателя Ивана Ловреновича: „Pravi akšamluk je rafinirana institucija kulture svakidašnjice, akšamluk je bosanska ekstaza”2 — „Настоящий «акшамлук» — это рафинированный институт культуры повседневности, «акшамлук» - это боснийский экстаз”.

Современное явление актуализации ориентализмов в языке боснийских мусульман можно проиллюстрировать еще одним весьма показательным примером с лексемой $a v a z$, которая пришла из персидского языка через турецкий в значении 'голос, пение, песня'. В прошлом ее употребление было ограничено религиозной сферой и являлось архаизированным. Толчком для актуализации и распространения данной лексемы в разговорном языке послужил факт начала выхода в 1995 г. многотиражной и самой популярной в Боснии и Герцеговине общенациональной ежедневной газеты „Dnevni avaz”, вследствие чего данная лексема приобретает „новую жизн” и переходит из сферы религиозного или фольклорного употребления в сферу разговорного языка и жаргона. Приведем следующие примеры употребления данного слова в таких актуализированных устойчивых сочетаниях, как (vikati, zvati) iz

${ }^{2}$ I. Lovrenović, Bosanski Hrvati: esej o agoniji jedne evropskoorijentalne mikrokulture, Zagreb 2002, c. 18 . 
avaza — „громко (кричать, звать), во весь голос”, jedna glava hiljadu avaza „болтун”, otvoriti avaz (kome) — „дать (кому) повод для разговоров”.

В заключение в рамках рассматриваемой темы нельзя не упомянуть и о такой лексико-синтаксической категории, характерной для всего южнославянского языкового арела, как устойчивые фразеологизированные клятвы, заклятия. Наряду с общими для всех южных славян заклятиями boga mi — „богом клянусь”, života mi — „жизнью клянусь”, majke mi — „матерью клянусь” и т. П. в Боснии довольно широко распространены аналогичные словосочетания-штампы, как: Allaha mi, pojma ti nemaš o tome! - „Аллахом клянусь, ты в этом ничего не понимаешь!”, Dolazim ja, rahmeta mi — „Я приду, клянусь покоем усопшего” и даже с повторением компонента для усиления экспрессии: Kunem se Allahom i rahmetom, istina je to! — „Клянусь Аллахом и покоем усопшего, это правда!”. Здесь следует отметить, что сама лексема Allah довольно часто встречается в речи боснийских мусульман в качестве синонимичного заменителя компонента в общих для южнославянского языкового пространства выражениях, как, например: Allah će znati (cp. Bog će znati), Ako Allah da (cp. Ako Bog da), восклицание Allah, Allah (cp. Bože, Bože!), удивление в звательном падеже Allahu sačuvaj (cp. Bože sačuvaj) и т. п., а междометное словосочетание, целиком заимствованное из Корана, Allahu ekber! часто используется для эмоционально-экспрессивного выражения удивления, восхищения.

Итак, на приведенных примерах нами был рассмотрен современный процесс актуализации ориентализмов в речи боснийских мусульман. Данное явление актуализации заимствований из восточных языков, как было показано выше, играет далеко не последнюю роль в формировании современного городского койне Сараева, его своеобразного языкового кода, а также молодежного жаргона и сленга, характерным и отличительным маркером которого выступают ориентализмы, получившие в последние десятилетия в силу различных причин „новую жизнь”. Подводя итог, следует также ометить, что многое из лексики и фразеологии боснийских мусульман, в основном, благодаря популяризации боснийской культуры, литературы, киноискусства, поэзии, сараевской бардовской песни, выходит за рамки данного микроареала и становится узнаваемым далеко за его пределами, сохраняя, при этом, свою маркированность и соотнесенность с местом своего происхождения, т. е. с Боснией.

\section{Библиография}

Halilović S., Tanović I., Šehović A., Govor grada Sarajeva i razgovorni bosanski jezik, Sarajevo 2009.

Hmelevskij M. S., Osobennosti frazeologii goroda Saraeva, [v:] Nacional'noe i internacional'noe v slavânskoj frazeologii, red. H. Walter, V. M. Mokienko, Greifswald 2013.

Hmelevskij M. S., Otraženie istorii, kul 'tury i tradicij Bosnii v âzykei frazeologii, „Studia Slavica Academiae Scientarum Hungaricae” 60, 2015, № 1. 
Lovrenović I., Bosanski Hrvati. Esej o agoniji jedne evropsko-orijentalne mikrokulture, Zagreb 2002.

Saračević N., Rječnik sarajevskog žargona — prilog leksikografiji bosanskoga jezika, Zenica 2007.

Saračević N., Rječnik sarajevskog žargona, Zenica 2009.

Šehović A., Haverić D., Leksika orijentalnog porijekla u frazemama bosanskog jezika, Sarajevo 2017.

Škaljić A., Turcizmi u srpskohrvatskom jeziku, Sarajevo 1989.

Tanović I., Frazeologija bosanskog jezika, Sarajevo 2000.

\section{The role of the process of updating orientalisms in the formation of Sarajevo's modern urban koiné}

Summary

The article discusses the process of updating orientalisms in the contemporary spoken language and the jargon of the inhabitants of Sarajevo. The examples illustrate the fact that lexemes of Turkish origin have expanded in recent decades their semantics in the language of Bosnian Muslims and have become a hallmark of their language identity. Particular attention was paid to the most characteristic terms and those reflecting the specificity of the mentality, culture and everyday life of the Muslim part of the BIH population. The material collected in 2009-2015 during scientific expeditions comes from interviews with Sarajevo residents, from new jargon dictionaries and texts present in the media and social networks.

Keywords: urban koiné, spoken language, orientalisms, semantic transformation, lexis, phraseology

\section{Uloga procesa aktualizacije orijentalizama u formisanju savremenog sarajevskog gradskog žargona}

\section{Rezime}

U ovom članku se razmatra aktuelni jezički proces aktualizacije orijentalizama u savremenom razgovornom jeziku stanovnika grada Sarajeva i njihovom žargonu. Pomoću navedenih primera se prikazuju činjenice kako lekseme uglavnom turskog porekla u zadnjim decenijama proširuju svoju semantiku u govoru bosanskih Muslimana i postaju svojvrsno obeležje njihovog jezičkog identiteta. Posebnu pažnju smo obratili na izraze koje najviše karakterišu i odražavaju specifičnost mentaliteta, kulture i svakodnevnog života muslimanskog dela stanovništva BiH. Građa za ovo istraživanje je sakupljena tokom naučnih ekspedicija 2009. - 2015. g. putem anketiranja govornika sarajevskog žargona te novih žargonskih rečnika, medija i socijalnih mreža.

Ključne reči: gradski žargon, razgovorni jezik, orijentalizmi, semantička transformacija, leksika, frazeologija 